\title{
THE RELATION BETWEEN STUDENT'S PERCEPTION OF LEARNING ENVIRONMENT AND LEARNING MOTIVATION OF PRE-CLINICAL MEDICAL STUDENT
}

\author{
Zafira Pringgoutami*, Rika Lisiswanti** , Dwita Oktaria** \\ * Mahasiswa, Fakultas Kedokteran, Universitas Lampung, Bandar Lampung - INDONESIA \\ ** Bagian Pendidikan Kedokteran, Fakultas Kedokteran, Universitas Lampung, Bandar Lampung - INDONESIA
}

\begin{abstract}
Background: Academic achievement is influenced by two factors, internal and external factor. Learning environment is one of the external factors that affect the academic achievement. A conducive learning environment can improve students learning motivation and affect academic achievement. The aim of this research is to find out the relation between student's perception of learning environment and learning motivation of pre-clinical student in Medical Faculty of Lampung University.

Methods: This research was using cross sectional approach. The sample of this research consisted 248 pre-clinical student in Medical Faculty of Lampung University which determined by proportional-random sampling. This research used two questionnaires: Dundee Ready Educational Environment Measure (DREEM) and Motivated Strategies of Learning Questionnaire (MSLQ). Data were analysed using Spearman.

Results: The result showed that most of pre-clinical student in Medical Faculty of Lampung University have perception about learning environment was decent (74,6\%) and learning motivation was high (98,8\%), there was significant relation between student's perception of learning environment and learning motivation which determined by $p$ value $<0,05$ and $r 0,462$.

Conclusion: From this research can be concluded that the better student's perceptions of learning environment, the higher learning motivation becomes.
\end{abstract}

Keywords: DREEM, learning environment, MSLQ, learning motivation

\begin{abstract}
ABSTRAK
Latar belakang: Pencapaian prestasi akademik dipengaruhi oleh dua faktor, yaitu faktor internal dan eksternal. Lingkungan belajar merupakan salah satu faktor eksternal yang memengaruhi pencapaian prestasi akademik. Lingkungan belajar yang kondusif dapat meningkatkan motivasi belajar mahasiswa dan berpengaruh terhadap prestasi akademik. Tujuan penelitian ini adalah untuk mengetahui hubungan persepsi mahasiswa tentang lingkungan belajar terhadap motivasi belajar pada mahasiswa tahap preklinik Fakultas Kedokteran Universitas Lampung.

Metode: Penelitian ini menggunakan pendekatan cross sectional. Sampel penelitian ini terdiri dari 248 mahasiswa tahap preklinik Fakultas Kedokteran Universitas Lampung yang ditentukan dengan proportional-random sampling. Penelitian ini menggunakan dua buah kuesioner yaitu Dundee Ready Educational Environment Measure (DREEM) dan Motivated Strategies of Learning Questionnaire (MSLQ). Analisis data menggunakan uji Spearman.

Hasil: Hasil penelitian ini menunjukkan sebagian besar mahasiswa tahap preklinik Fakultas Kedokteran Universitas Lampung memiliki persepsi tentang lingkungan belajar yang cukup memuaskan $(74,6 \%)$ dan motivasi belajar yang tinggi (98,8\%), serta terdapat hubungan bermakna antara persepsi mahasiswa tentang lingkungan belajar terhadap motivasi belajar dengan nilai $p<0,05$ dan $r$ 0,462.
\end{abstract}

contact: pringgoutami@gmail.com 
Kesimpulan: Dari penelitian ini dapat disimpulkan bahwa semakin baik persepsi mahasiswa tentang lingkungan belajar, semakin tinggi motivasi belajarnya.

Kata kunci: DREEM, lingkungan belajar, MSLQ, motivasi belajar

\section{PENDAHULUAN}

Keberhasilan belajar mahasiswa dapat dilihat dari pencapaian prestasi akademik. Pencapaian prestasi akademik dipengaruhi oleh dua faktor, yaitu faktor internal dan eksternal. ${ }^{1}$ Salah satu faktor eksternal yang memengaruhi pencapaian prestasi akademik adalah lingkungan belajar. Lingkungan belajar merupakan pengalaman atau persepsi pelajar yang akan menjadi iklim pembelajaran dan mempengaruhi perilaku pelajar. Lingkungan belajar yang kondusif dapat meningkatkan motivasi belajar mahasiswa dan berpengaruh terhadap prestasi akademik. ${ }^{2,3}$

Lingkungan belajar dapat diukur dengan Dundee Ready Educational Environment Measure (DREEM). Kuesioner ini merupakan alat ukur yang telah valid, reliabel, dan banyak digunakan oleh berbagai negara untuk menilai iklim pembelajaran pendidikan kedokteran melalui persepsi mahasiswa terhadap lingkungan belajarnya dan dibuat untuk menyempurnakan instrumen lingkungan belajar terdahulu. ${ }^{4}$ DREEM terdiri dari 5 dimensi yaitu persepsi mahasiswa terhadap proses pembelajaran, persepsi mahasiswa terhadap dosen, persepsi mahasiswa terhadap pencapaian akademik, persepsi mahasiswa terhadap suasana pembelajaran, Persepsi mahasiswa terhadap lingkungan sosial. ${ }^{5}$

Motivasi adalah dorongan dalam pribadi seseorang untuk terlibat dalam perilaku tertentu sebagai usahanya untuk mencapai suatu tujuan. Sementara motivasi belajar adalah kecenderungan mahasiswa dalam belajar yang didorong oleh hasrat untuk mencapai hasil belajar sebaik mungkin. Menurut self-determination theory yang dikembangkan oleh Deci dan Ryan, membedakan motivasi menjadi dua jenis berdasarkan perspektif kualitasnya, yaitu motivasi intrinsik dan ekstrinsik. Motivasi intrinsik adalah motivasi yang bersumber dari individu itu sendiri tanpa ada paksaan dari orang lain.
Sedangkan motivasi ekstrinsik adalah motivasi akibat pengaruh dari luar individu berupa ajakan, suruhan maupun paksaan dari orang lain agar individu mau melakukan perilaku tersebut. Kualitas motivasi belajar dapat berubah baik dari intrinsik ke ekstrinsik maupun sebaliknya bersamaan dengan berjalannya waktu, kedewasaan, dan pengalaman individu di lingkungan belajarnya. ${ }^{6,7}$

Motivasi belajar dapat diukur dengan Motivated Strategies of Learning Questionnaire (MSLQ). Kuesioner ini dikembangkan oleh Pintrich untuk menilai orientasi motivasi dan strategi belajar mahasiswa. Motivasi dalam kuesioner ini terdiri dari tiga komponen yaitu komponen nilai, komponen harapan, dan komponen afektif. Komponen nilai terdiri dari tiga dimensi yaitu motivasi intrinsik, motivasi ekstrinsik, dan task value. Kompeten harapan terdiri dari control of learning beliefs dan self efficacy for learning and performance. Dan Terdapat satu dimensi untuk menilai komponen afektif yaitu tes kecemasan. ${ }^{8,9}$

Beberapa peneliti menyatakan bahwa terdapat hubungan antara lingkungan belajar dan motivasi belajar. Penelitian oleh Radovan dan Makovec pada tahun 2015 mengenai lingkungan belajar di Faculty of Arts at the University of Ljubljana menyatakan bahwa terdapat hubungan yang positif antara motivasi dan lingkungan belajar. ${ }^{10}$ Dan dalam penelitian pada mahasiswa keperawatan di Shiraz University of Medical Sciences juga menunjukkan bahwa lingkungan belajar memiliki pengaruh yang signifikan terhadap motivasi belajar mahasiswa. Lingkungan belajar yang suportif dapat meningkatkan motivasi belajar. ${ }^{11}$ Penelitian ini bertujuan untuk mengetahui hubungan persepsi mahasiswa tentang lingkungan belajar terhadap motivasi belajar pada mahasiswa tahap preklinik Fakultas Kedokteran Universitas Lampung (FK Unila). 


\section{METODE}

Jenis penelitian ini menggunakan metode penelitian analitik observasional dengan bentuk studi cross sectional. Penelitian dilaksanakan pada bulan September-Oktober 2017 di Fakultas Kedokteran Universitas Lampung. Sampel penelitian ini terdiri dari 248 mahasiswa tahap preklinik Fakultas Kedokteran Universitas Lampung yang ditentukan dengan proportional-random sampling. Kriteria inklusi sampel pada penelitian ini adalah seluruh mahasiswa tahap preklinik Fakultas Kedokteran Universitas Lampung dan mahasiswa yang bersedia menjadi responden. Sedangkan kriteria eksklusi sampel terdiri dari mahasiswa yang tidak hadir dalam penelitian dan yang tidak mengumpulkan kuesioner.

Variabel penelitian terdiri dari dua variabel, yaitu variabel dependen dan independen. Pada penelitian ini, lingkungan belajar merupakan variabel independen. Sedangkan motivasi belajar merupakan variabel dependen. Pengambilan data primer persepsi mahasiswa tentang lingkungan belajar dilakukan dengan kuesioner Dundee Ready Educational Environment (DREEM). Kuesioner ini diambil dari penelitian Leman tahun 2014 yang kemudian divalidasi kembali terhadap 40 responden mahasiswa tahap preklinik Fakultas Kedokteran Universitas Malahayati. ${ }^{12}$ Setelah dilakukan uji validitas, kuesioner ini terdiri dari 37 pertanyaan dengan $r$ hitung lebih besar dari $r$ tabel yaitu $r>0,26$. Reliabitas dengan Cronbach's alpha didapatkan hasil 0,939. Hal ini membuktikan 37 item pertanyaan kuesioner ini reliabel.

Data primer motivasi belajar diukur dengan Motivated Strategies of Learning Questionnaire (MSLQ), yang diambil dari penelitian Lisiswanti, Sanusi dan Prihatiningsih pada tahun 2015. Kuesioner ini terdiri dari 31 pertanyaan. Uji validitas dan reliabilitas yang dilakukan didapatkan $r$ hitung lebih besar dari $r$ tabel yaitu $r>0,3$ dan Cronbach's alpha 0,846.

Data penelitian diambil setelah mendapatkan persetujuan etik dari komisi etik penelitian Fakultas
Kedokteran Universitas Lampung. Pengambilan data dilakukan berdasarkan persetujuan mahasiswa untuk menjadi responden. Analisis data penelitian ini menggunakan uji Spearman.

\section{HASIL DAN PEMBAHASAN}

Berikut karakteristik responden berdasarkan jenis kelamin dan angkatan:

Tabel 1.Karakteristik subjek penelitian

\begin{tabular}{crc} 
Karakteristik & $\mathbf{N}$ & $\%$ \\
\hline Jenis kelamin & & \\
Laki-laki & 63 & $25,4 \%$ \\
Perempuan & 185 & $74,6 \%$ \\
Angkatan & & \\
2014 & 86 & $34,7 \%$ \\
2015 & 71 & $28,6 \%$ \\
2016 & 91 & $36,7 \%$ \\
\hline
\end{tabular}

Skor persepsi mahasiswa tentang lingkungan belajar yang diukur dengan kuesioner DREEM mendapatkan hasil rerata 105 , skor minimal 70, dan skor makasimal 142. Selanjutnya, skor tersebut dibagi menjadi 4 kategori yaitu sangat tidak memuaskan, banyak permasalahan, cukup memuaskan, dan sangat memuaskan. Pada tabel 2, terlihat bahwa kategori persepsi mahasiswa tentang lingkungan belajar FK Unila yang paling dominan adalah cukup memuaskan dengan persentase $74,6 \%$.

Tabel 2. Persepsi mahasiswa tentang lingkungan belajar

\begin{tabular}{lrc}
\multicolumn{1}{c}{ Kategori } & N & \% \\
Sangat tidak memuaskan & 0 & $0 \%$ \\
Banyak permasalahan & 3 & $1,2 \%$ \\
Cukup memuaskan & 185 & $74,6 \%$ \\
Sangat memuaskan & 60 & $24,2 \%$ \\
\hline
\end{tabular}

Hasil rata-rata nilai tiap dimensi DREEM disajikan .dalam Tabel 3 di bawah ini 
Tabel 3. Rata-rata nilai dimensi DREEM

\begin{tabular}{lc}
\multicolumn{1}{c}{ Dimensi (nilai maksimal) } & $\begin{array}{c}\text { Skor rata-rata } \\
\text { (mean score) }\end{array}$ \\
Persepsi mahasiswa terhadap proses pembelajaran (32) & $23(2,88)$ \\
Persepsi mahasiswa terhadap dosen (36) & $25(2,78)$ \\
Persepsi mahasiswa terhadap suasana pembelajaran (36) & $25(2,78)$ \\
Persepsi mahasiswa terhadap pencapaian akademik (20) & $15(3)$ \\
Persepsi mahasiswa terhadap lingkungan sosial (24) & $17(2,83)$ \\
\hline
\end{tabular}

Nilai rerata 105/148 menunjukkan bahwa mahasiswa menganggap lingkungan belajar yang ada saat ini, termasuk proses pembelajaran, dosen, suasana pembelajaran, pencapaian akademik, dan lingkungan sosial berada dalam lingkungan yang cukup memuaskan dan lebih bernilai positif. Dan rata-rata nilai total dan masing masing dimensi berada pada kisaran 2-3 yang menunjukkan bahwa terdapat beberapa aspek lingkungan belajar di FK Unila yang masih dapat ditingkatkan. Lingkungan belajar yang ditingkatkan akan memberikan manfaat bagi pelajar yaitu dari segi kenyamanan, percaya diri, tanggung jawab, pengetahuan, keterampilan, kesempatan belajar, dan model untuk praktik. ${ }^{5}$

Analisis setiap dimensi menunjukkan bahwa kepuasan tertinggi mahasiswa terhadap lingkungan belajar FK Unila berada pada pencapaian akademik, sedangkan kepuasan terendah berada pada dosen dan suasana pembelajaran. Pada dimensi persepsi mahasiswa terhadap pencapaian akademik memiliki mean score 3. Hal ini menunjukkan proses pembelajaran memiliki poin positif yaitu mahasiswa merasa telah dipersiapkan dengan baik untuk menjadi seorang dokter, telah belajar banyak tentang empati, dan sebagian besar yang dipelajari relevan dengan karirnya di bidang kesehatan. Dari semua item dalam domain ini, skor terendah terdapat pada pernyataan "keterampilan untuk memecahkan masalah (problem solving) saya berkembang dengan baik". Keadaan serupa juga ditemukan pada penelitian yang dilakukan oleh Shafira, Jusuf, dan Budiningsih ${ }^{13}$ di Program Studi Pendidikan Dokter Universitas Jambi. Hal ini menunjukkan kemampuan problem solving mahasiswa tahap preklinik FK Unila dapat lebih ditingkatkan. Kemampuan ini dapat ditingkatkan melalui proses diskusi tutorial yang berjalan dengan baik. ${ }^{13}$
Dalam dimensi persepsi mahasiswa terhadap dosen dan suasana pembelajaran diperoleh mean score 2,78. Skor ini berada pada kisaran 2-3 sehingga masih terdapat beberapa aspek yang perlu ditingkatkan atau diperbaiki. Aspek dosen yang perlu ditingkatkan atau diperbaiki antara lain: kesabaran dosen $(2,63)$, sikap dosen yang meremehkan mahasiswa $(2,67)$, umpan balik dari dosen $(2,86)$, kritik $(2,97)$, memberikan contoh yang jelas $(2,87)$, dan persiapan sebelum mengajar $(2,95)$. Mahasiswa tahap preklinik FK Unila merasa bahwa dosen telah memiliki pengetahuan yang baik, namun masih terdapat mahasiswa yang bersikap kurang baik terhadap dosen. Mahasiswa yang bersikap kurang baik terhadap dosen ini diindikasikan sebagai permasalahan dan perlu diperhatikan lebih lanjut. Sementara semua aspek dalam suasana pembelajaran masih perlu untuk ditingkatkan, terutama pada aspek kenyamanan suasana belajar $(2,4)$.

Pada dimensi persepsi mahasiswa terhadap proses pembelajaran, sebagian besar mahasiswa termotivasi untuk berpartisipasi aktif dalam perkuliahan, dan merasa perkuliahan membantu mengembangkan kompetensinya. Rata-rata skor per item dalam domain ini adalah 2-3, sehingga proses pembelajaran di FK Unila masih dapat ditingkatkan, terutama efektivitas waktu perkuliahan.

Dalam dimensi persepsi mahasiswa terhadap lingkungan sosial, ditemukan skor terendah kurang dari 2 pada item "terdapat sistem penunjang yang baik bagi mahasiswa yang stres". Hasil ini juga sejalan dengan penelitian sebelumnya oleh Kohli dan Dhaliwal (2015) di University College of Medical Sciences, India. Hal ini menunjukkan bahwa mahasiswa merasa sistem penunjang stres di FK Unila perlu mendapatkan perhatian. 
Sebenarnya sistem penunjang stres di FK Unila telah menerapkan bimbingan dan konseling serta kegiatan mentoring bagi mahasiswa tingkat pertama sebagai upaya memecahkan masalah mahasiswa. Sistem ini dapat lebih ditingkatkan dengan melanjutkan kegiatan mentoring bagi mahasiswa senior dan intervensi langsung kepada mahasiswa. Sebagai contoh, seperti intervensi stres singkat yang dilakukan Yusoff di School of Medical Science Universiti Sains Malaysia. Intervensi ini diakukan dengan cara memberikan kuliah mengenai konsep stres, stressor yang berhubungan dengan kedokteran, dan coping strategies; kemudian mengisi kuesioner untuk mengetahui tingkat stres dan stressor yang mahasiswa hadapi, setelah itu dilanjutkan dengan kuliah cara mengatasi stres dan diskusi antara mahasiswa dan fasilitator. ${ }^{14}$

FK Unila menerapkan Kurikulum Berbasis Kompetensi (KBK) dengan metode pembelajaran problem-based learning (PBL). Melalui metode ini, mahasiswa diharapkan lebih termotivasi dan bertanggung jawab terhadap lingkungan belajarnya. Sehingga hal ini dapat dijadikan penyebab bagi mahasiswa dalam penelitian ini untuk memberikan penilaian lingkungan belajar FK Unila yang lebih positif, karena mahasiswa telah terbiasa dengan pendekatan PBL sejak menjalani pendidikan kedokteran. Selain itu, variabilitas kriteria dan harapan mahasiswa akan lingkungan belajarnya juga berpengaruh terhadap penilaian lingkungan belajar. ${ }^{15}$

Skor motivasi belajar yang diukur dengan MSLQ mendapatkan hasil rerata 176 , skor terendah 112 , dan skor tertinggi 215 dari maksimal skor 217. Rata-rata ini menunjukkan bahwa motivasi belajar mahasiswa tahap preklinik FK Unila cukup tinggi yaitu lima sampai enam dari tujuh skala tertinggi. Hasil ini sesuai dengan penelitannya sebelumnya oleh Lisiswanti et al ${ }^{16}$ yang menunjukkan rata-rata motivasi cukup tinggi yaitu lima dari tujuh skala tertinggi.

Selanjutnya, skor tersebut dibagi menjadi dua kategori yaitu rendah (31-124) dan tinggi (125217). Pada Tabel 4, dapat diketahui bahwa sebagian besar mahasiswa tahap preklinik FK Unila memiliki motivasi belajar yang tinggi.

Tabel 4. Motivasi belajar mahasiswa

\begin{tabular}{lrr} 
Kategori & $\mathbf{N}$ & \multicolumn{1}{c}{$\%$} \\
Rendah & 3 & $1,2 \%$ \\
Tinggi & 245 & $98,8 \%$ \\
\hline
\end{tabular}

Hasil rata-rata nilai tiap dimensi MSLQ disajikan dalam Tabel 5 di bawah ini.

Tabel 5. Rata-rata nilai dimensi MSLQ

\begin{tabular}{ll}
\multicolumn{1}{c}{ Dimensi (nilai maksimal) } & \multicolumn{1}{c}{$\begin{array}{c}\text { Rerata nilai } \\
\text { (mean score) }\end{array}$} \\
\hline Motivasi intrinsik (28) & $23,5(5,88)$ \\
Motivasi ekstrinsik (28) & $24(6)$ \\
Task value (42) & $36(6)$ \\
Control of learning beliefs (28) & $24(6)$ \\
Self efficacy for learning and performance (56) & $44(5,5)$ \\
Anxiety test (35) & $26(5,2)$ \\
\hline
\end{tabular}

Motivasi intrinsik adalah dorongan atau kehendak yang ada dalam diri seseorang untuk melakukan aktivitas. Motivasi intrinsik biasanya bertolak belakang dengan motivasi ekstrinsik yang dipengaruhi oleh dorongan dari luar. Nilai dari motivasi intrinsik dan ekstrinsik sebenarnya tergantung pada lama keterlibatan dan kompleksitas tugas. Motivasi intrinsik memang sangat menentukan, akan tetapi tidak semua pelajar termotivasi secara intrinsik, bahkan pelajar yang termotivasi pun terkadang dapat menjadi tidak termotivasi. Oleh karena itu, pada beberapa kasus, kombinasi dari motivasi ekstrinsik dan faktor lingkungan dapat menjadi faktor penentu 
keberhasilan belajar pada pelajar yang cenderung memiliki motivasi rendah. ${ }^{17}$

Selain motivasi intrinsik dan ekstrinsik, control of learning beliefs mahasiswa tahap preklinik FK Unila juga tinggi dengan rerata skor 6 . Perasaan dapat mengontrol kesuksesan dan kegagalan membuat individu semakin termotivasi. Jika mahasiswa percaya bahwa usaha belajar akan mempengaruhi hasil belajarnya, maka mereka akan menggunakan strategi yang efektif. Self-efficacy hasil penelitian ini juga tinggi dengan rerata skor 5,5. Selfefficacy adalah kepercayaan seseorang terhadap kemampuan dirinya untuk memecahkan masalah atau mengerjakan tugas. Individu dengan selfefficacy yang tinggi cenderung lebih termotivasi dan sukses dalam mengerjakan tugas. Tingkat kecemasan mahasiswa tahap preklinik FK Unila cukup tinggi yaitu 5,2. Hal ini menunjukkan bahwa mahasiswa memiliki tingkat kecemasan yang tinggi terhadap proses pembelajaran. ${ }^{9,17}$

Penelitian ini memilih uji hipotesis korelatif Spearman untuk mengetahui hubungan antara persepsi mahasiswa terhadap lingkungan belajar dengan motivasi belajar pada mahasiswa tahap preklinik FK Unila. Uji tersebut digunakan karena distribusi data persepsi mahasiswa tentang lingkungan belajar dan data motivasi belajar tidak normal. Hasil uji korelasi Spearman ditampilkan dalam Tabel 6 di bawah ini.

Tabel 6. Hasil uji korelasi Spearman

\begin{tabular}{lc} 
& Motivasi belajar \\
Persepsi mahasiswa tentang & $\mathrm{r}=0,462$ \\
lingkungan belajar & $\mathrm{p}=0,000$ \\
& $\mathrm{n}=248$ \\
\hline
\end{tabular}

Nilai $\mathrm{p}<0,05$ yaitu sebesar 0,000, maka dapat disimpulkan bahwa terdapat hubungan antara persepsi mahasiswa tentang lingkungan belajar terhadap motivasi belajar pada mahasiswa tahap preklinik FK Unila. Nilai $\mathrm{r}=0,462$ menunjukkan hubungan yang positif dan kekuatan korelasi antara persepsi mahasiswa tentang lingkungan belajar dan motivasi belajar dikategorikan sedang. ${ }^{18}$ Hasil penelitian ini mendukung teori yang dikemukakan
Kusurkar yaitu motivasi dipengaruhi oleh lingkungan belajar dimana kualitas motivasi belajar dapat berubah baik dari intrinsik ke ekstrinsik maupun sebaliknya bersamaan dengan berjalannya waktu, kedewasaan, dan pengalaman individu di lingkungan belajarnya. ${ }^{?}$

Penelitian ini juga sejalan dengan penelitian sebelumnya di di Faculty of Arts at the University of Ljubljana pada tahun 2015 dan di Shiraz University of Medical Sciences pada tahun 2016 yang menunjukkan hubungan yang positif antara persepsi mahasiswa tentang lingkungan belajar dengan motivasi. Hasil penelitian menggambarkan mahasiswa dengan persepsi lingkungan belajar sebagai lingkungan yang berguna untuk proses pembelajaran dan berusaha untuk menyesuaikan dirinya, termotivasi secara intrinsik dan ekstrinsik. ${ }^{10,11}$

\section{KESIMPULAN}

Terdapat hubungan bermakna antara persepsi mahasiswa terhadap lingkungan belajar dengan motivasi belajar pada mahasiswa tahap preklinik Fakultas Kedokteran Universitas Lampung. Persepsi mahasiswa tentang lingkungan belajar FK Unila sebagian besar cukup memuaskan. Dan sebagian besar motivasi belajar mahasiswa tahap preklinik FK Unila tergolong tinggi.

\section{DAFTAR PUSTAKA}

1. Suprapti. Faktor eksternal yang mempengaruhi tingginya prestasi belajar mahasiswa tingkat II di STIKES Widya Dharma Husada Tanggerang. Jurnal Kesehatan Dan Budaya. 2015; 8(2): 1.

2. Dent J, Harden RM. A practical guide for medical teachers. London: Elsevier; 2009.

3. Naibaho H, Adi F, Veryco, Sugiarto. Pengaruh lingkungan kampus terhadap motivasi belajar mahasiswa. Jurnal Manajemen Pemasaran. 2010; 5(1): 22-26.

4. Roff S. The Dundee Ready Education Environment Measure (DREEM): a generic instrument for measuring student's perception of undergraduate health profession curricula. Medical Teacher. 2005; 27 (4): 322-5.

5. Genn JM. AMEE Medical Education Guide No. 23 (Part 2): Curriculum, environment, climate, quality 
and change in medical education - a unifying perspective. Medical Teacher. 2001; 23(5): 445-54.

6. Anwar AI, Prabandari YS, Emilia O. Motivasi dan strategi belajar siswa dalam pendidikan pembelajaran berbasis masalah dan collaborative learning di fakultas kedokteran gigi universitas hasanuddin. Jurnal Pendidikan Kedokteran Indonesia. 2013; 2(3): 233-8

7. Kusurkar RA. Motivation in medical students. Oisterwijk: Uitgeverij BOXPress; 2012.

8. Pintrich PR, Smith DA, Garcia T, Mckeachie WJ. A manual for the use Motivated Strategies for Learning Questionnaire (MSLQ). Washington: Educational Research and Improvement; 1991.

9. Taylor RT. Review of the Motivated Strategy for Learning Questionnaire (MSLQ) using reliability generalization techniques assess scale reliability [disertasi]. Alabama: Auburn University; 2012.

10. Radovan M, Makovec D. Adult learners' learning environment perceptions and satisfaction in formal education-case study of four East-European countries. International Education Studies. 2015; (2): 101-112.

11. Hayat AA, Kohoulat N, Dehgani MR, Kojuri J, Amini M.Students' perceived learning environment and extrinsic and intrinsic motivation. 2016; IJHCS 3(2): 1000-8.
12. Leman MA. Penilaian validitas konstruk Dundee Ready Educational Environment Measurement (DREEM) di Program Studi Pendidikan Dokter Gigi Fakultas Kedokteran Universitas Sam Ratulangi Manado. Jurnal Pendidikan Kedokteran Indonesia 2014; 6(1): 11-9

13. Shafira NNA, Jusuf A, Budiningsih S. Hubungan persepsi lingkungan pembelajaran dengan strategi pembelajaran mahasiswa Program Studi Pendidikan Dokter Universitas Jambi. Jurnal Pendidikan Kedokteran Indonesia 3 2014; (1): 28-37.

14. Kohli V, Dhaliwal U. Medical students' perception of the educational environment in a medical college in India: a cross-sectional study using the Dundee Ready Education Environment questionnaire. J Educ Eval Health Prof 2013; 10: 5

15. Abraham R, Ramnarayan K, Vinod P, Torke S. Students perceptions of learning environment in an Indian Medical School. Biomed Central 2008; $8(20): 1-5$.

16. Lisiswanti R, Sanusi R, Prihatiningsih TS. Hubungan motivasi dan hasil belajar mahasiswa kedokteran. Jurnal Pendidikan Kedokteran Indonesia. 2015; 4(1): 1-6.

17. Lai ER. Motivation: A literature review. Always Learning Pearson; 2011.

18. Dahlan MS. Statistik untuk kedokteran dan kesehatan. Jakarta: Epidemiologi Indonesia; 2014. 